
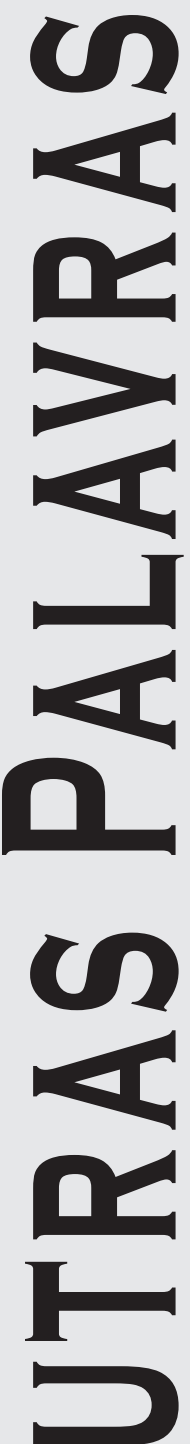

Revista Música Hodie, Goiânia - V.16, 209p., n.1, 2016 


\title{
Juventude, música e cinema em Manaus na década de 1960: da diversão à aprendizagem musical ${ }^{1}$
}

\author{
Lucyanne de Melo Afonso (Universidade Federal do Amazonas, Manaus, AM, Brasil)² \\ lucyanneafonso@hotmail.com
}

\begin{abstract}
Resumo: O trabalho buscou compreender a função do cinema no circuito musical em Manaus na década de 1960. Para as análises foram utilizados jornais da década de 1960 e entrevistas com músicos que participaram ativamente deste circuito. Temos como considerações que o cinema foi um mediador tanto para a diversão quanto para a aprendizagem musical; no cinema podia observar como o artista se comportava em palco, seus gestos e vestimentas, e, posteriormente, os jovens iam para os clubes da cidade realizar dublagens, sendo as dublagens uma vida real mítica de representar o sonho de ser o próprio ídolo.
\end{abstract}

Palavras-chave: Cinema em Manaus; Juventude; Formação musical; Dublagem em Manaus.

Youth, music and film in Manaus in the 1960s: the fun of musical learning

Abstract: The study sought to understand the role of cinema in the musical circuit in Manaus in the 1960s for the analyzes were used newspapers from the 1960s and interviews with musicians who actively participated in this circuit. We as considerations that cinema was a mediator both for fun and for learning music; the film could be seen as the artist was acting on stage, his gestures and clothing, and later, young people went to the clubs in town performing voiceovers, and the voiceovers a real mythical life to represent the dream of being the idol itself..

Keywords: Film in Manaus; Youth; Music training; Dubbing in Manaus.

Juventud, música y el cine en Manaus, en la década de 1960: la diversión de aprendizaje musical

Resumen: El estudio trata de comprender el papel del cine en el circuito musical en Manaus, en la década de 1960 para los análisis se utilizaron los periódicos de la década de 1960 y las entrevistas con los músicos que participaron activamente en este circuito. Nosotros, como las consideraciones que el cine era un mediador tanto para la diversión y para el aprendizaje de la música; la película podría ser visto como el artista estaba actuando en el escenario, sus gestos y de la confección, y más tarde, los jóvenes se dirigió a los clubes de la ciudad la realización de la voz en off, y las voces en off de una auténtica vida mítica para representar el sueño de ser el ídolo de sí mismo.

Palabras clave: Cine en Manaus; La juventud; Formación musical; Doblaje en Manaus.

\section{Introdução: processos metodológicos}

O trabalho apresenta uma investigação sobre a relação do cinema com a juventude e sua função de entreter e educar, com objetivo de analisar o papel do cinema dentro do circuito musical em Manaus, buscando compreender e identificar as relações socioculturais estabelecidas entre a cidade, a música e os espaços.

Tratou-se de um trabalho investigativo de coleta e análise de dados, sendo uma pesquisa qualitativa de cunho exploratório por meio de pesquisa documental direta e indireta. A pesquisa documental "é trabalhada com documentos que não receberam análise e síntese” (idem, 192) suas vantagens "são a confiança nas fontes documentais, como essenciais para qualquer estudo, o baixo custo e o contato do pesquisador com documentos originais (ibidem, p. 192).

Para Santos (2010) a pesquisa documental direta compreende "todos os tipos de documentos escritos, como livros, periódicos, jornais, revistas, filmes, fotografias, etc.” (p. 201). Nesta metodologia, utilizamos as notas do Jornal do Commercio da década de 1960 que foi possível mapear os cinemas, os filmes e os artistas apresentados.

A pesquisa documental indireta compreende a aplicação de entrevistas que pode estruturada ou não-estruturada ou na aplicação de questionários para obter dados através da história oral. Na entrevista podemos averiguar a visão de cada um sobre os mesmos fatos, sobre qual aspecto cada entrevistado se deteve, eternizando sua experiência e vivên- 
cia. As entrevistas com músicos que vivenciaram este período como Adelson Santos, Noval Benaion, Lili Andrade, Zeca Torres, Delfim de Sá, Edinelza Sahado, foram essenciais para compreender e identificar as relações que o cinema exercia no circuito de Manaus na década de 1960.

\section{Caminhos epistemológicos}

Desde a Segunda Guerra Mundial com a política da Boa Vizinhança entre Brasil e Estados Unidos o intercâmbio cultural representou a troca de culturas: era mais uma exportação da cultura americana do que importação.

O Brasil liberou a entrada de filmes e músicas dos Estados Unidos que passaram a fazer parte da programação das nossas rádios e dos nossos cinemas. Influenciou cantores e compositores de todo o Brasil, fez com que as estrelas do cinema, os ídolos de Hollywood fossem ídolos aqui também. Entretanto, passaram a ocupar boa parte da programação das emissoras de rádio brasileira, com a exportação do rock and roll, como comenta Cabral (2011).

O Brasil não ofereceu qualquer restrição à entrada de filmes e músicas dos Estados Unidos no Brasil. Os ídolos de Hollywood eram tão ídolos lá quanto aqui. E a música norte-americana, que passou a ocupar grande parte das programações das nossas emissoras de rádio e que aqui chegava em quantidades imensas, tanto em disco quanto através do cinema. (p. 113)

De acordo com Seren (2011, p. 80) a década de 1950 colaborou para a formação de uma nova sociedade através da mídia: os discos, o rádio e o cinema.

Todo produto cultural: música, cinema, teatro, a literatura dos Estados Unidos entrava no Brasil com muita facilidade. O brasileiro passou a conviver com a vida americana diariamente e a estabelecer os padrões de gosto pelo o que era apreciado: os ritmos americanos e, principalmente o cinema influenciaram na escuta e na preferência da música.

Tinhorão (1997) destaca a presença desse bombardeamento do cinema e dos discos como um modelo americano de forma de vida:

Os Estados Unidos interessados em provar as suas excelências do american way of life, forneciam amplo material através da propaganda de guerra (revista Em Guarda), cultural (tablóide Pensamento da América encartado pelo jornal A Manhã, e cursos de língua inglesa), diversão (filmes de Hollywood e histórias em quadrinhos) e musical, aqui através do duplo bombardeamento do cinema e dos discos, que então invadiram o mercado brasileiro impondo o estilo cool dos seus cantores sussurrantes. (p. 57)

Para Benjamin (1969, p. 230) o cinema enriqueceu nossa atenção e revelou o mundo: “O que caracteriza o cinema não é apenas a maneira pela qual o homem se apresenta ao aparelho, mas também o modo pelo qual ele figura na representação - devido a este aparelho - o mundo que o cerca."

Músicas de vários cantores e grupos americanos como Byrds, Crosby, Stills, Nash \& Young, Jefferson's Airplane, Allman Brothers Band; Ramblin Man, Blue Sky, Jessica, Lynyrd Skynyrd, Joni Mitchell; Big Yellow Taxi, The Platters, John Denver, Jimi Hendrix, Bob Dylan, Elvis Presley, Beatles, entre outros, foram os hits das rádios e dos musicais no cinema.

Em Manaus, na década de 1960, a rádio estava no seu auge, logo foi o condicionador dessas preferências e gostos, mas o cinema foi também um gerador de atitudes e comportamentos, tendo em vista que é anterior ao rádio na cidade de Manaus. 
Assim, uma juventude emergiu ao som da cultura internacional popular, o rock and roll e o jazz, que ditava a moda e o comportamento da época, sendo a rádio e o cinema os melhores instrumentos de distribuição dessa música, alcançando maior número de ouvintes e possibilitando os desejos dos jovens, a influencia de foram positiva na formação musical e comportamento da época.

Para Bloom (1991, p. 57) que retrata a influência na poesia: a presença de outros poetas na sua própria poesia, daí surgem outras experiências em que se descobre a experiências de outros eus.

Um poeta exerce influência sobre a obra do outro, vamos transferir para a música: a obra de um músico exerce influência sobre a obra do outro. A influência simplesmente acontece de um artista influenciar a obra de outro, de acordo com Bloom (2001):

simplesmente acontece: acontece de um poeta exercer influência sobre o outro; mais precisamente, os poemas de determinado poeta influenciam os poemas de outro, através de generosidade de espírito, talvez mesmo uma generosidade compartilhada. (p. 62)

Por outro lado, Fubini (2003, p. 37) retrata bem esta questão da influência de Bloom (2001): “cada geração de músicos toma geralmente como modelo o seu mestre, mas nunca recorre a um modelo exemplar de classicidade". O "modelo" em Fubini (2003) é, em outras palavras, o empréstimo de nossos conhecimentos a outra geração.

Não diferente aconteceu com a música em Manaus, onde os jovens locais tiveram como "modelo" (Fubini, 2003) ou como "influência” (Bloom, 2001) outros artistas que a "indústria cultural" apresentava no cinema e no rádio.

É preciso enfatizar que Manaus, na década de 1960, foi uma cidade moldada para o progresso: abrindo estradas e incentivando o comércio. Todas estas questões influenciaram no circuito musical, principalmente a indústria cultural que solidificava sua permanência global através de seus produtos. Assim, temos o cinema inserido neste espaço sociocultural como educador de um gosto musical e educador do consumo, tendo uma função de entreter e educar.

\section{Nas telas do cinema em Manaus}

O cinema virou palco para os grandes cantores que participavam dos filmes musicais brasileiros. Não somente era o ato de cantar, mas se fazia nos palcos do cinema o que era feito nos filmes musicais.

Orlando Dias (1923-2001) foi um exemplo de cantor popular que se apresentava nos cinemas pelas suas performances diferenciadas: além da bela voz, os gestos e as expressões estavam presentes.

Cabral (2011) descreve o cantor Orlando Dias como um cantor muito popular, além de apresentar os cantores pelos quais se inspirava devido às características individuais, levando a ter nas suas performances a junção da voz de Francisco Alves (1898-1952) e a interpretação de Silvio Caldas (1908-1998).

Sua popularidade levou-o a ganhar o título de $O$ cantor das multidões, criado pelo radialista Oduvaldo Cozzi. Dono de um belíssimo timbre de voz, ele costumava dizer, nas entrevistas, que o seu jeito de cantar, nasceu de uma decisão tomada no momento em que percebera que teria pela frente dois outros grandes cantores: Francisco Alves e Sílvio Caldas. "Francisco Alves tinha a voz e Sílvio Caldas, interpretação. Entrei no meio dos dois", contava. (p. 49) 
A notícia do Jornal A Crítica de 10 março de 1961 divulgava o cantor Orlando Dias que estrearia no Cine Ypiranga, no bairro da Cachoeirinha. A notícia comenta a respeito do cantor Orlando Silva como sendo o grande cartaz da atualidade em todo o Brasil: "cantor consagrado, artista completo que no palco, ri, chora, fica de joelhos, faz promessa, acende vela, crava um punhal no peito... e morre".

Amanhã finalmente: Grande Estréia de Orlando Dias, no "Cine Ypiranga". Amanhã, finalmente toda a cidade assistirá no Cine-Teatro Ipiranga na cachoeirinha a grande estreia de ORLANDO DIAS, o maior cartaz da atualidade em todo o Brasil. Cantor consagrado, artista completo que no palco ri, hora, fica de joelhos, faz promessas, acende vela, crava punhal no peito e... "morre". Orlando Dias dono de um repertório fabuloso, será a garantia de um excelente fim de semana para os apreciadores da música romântica já que da sua galeria fazem parte inúmeros sucessos. Por exemplo: "Tu hás de pensar em mim", "Perdoa-me pelo bem que te quero", "Minha serás eternamente", "Por uma noite ainda", "Ainda te espero", "Nas tuas horas de tristeza", "Nunca mais", "Quem ama perdoa", "Eu te quero tanto", e muitas outras lindas gravações que ORLANDO DIAS profeta na voz a tristeza de um solidão inconformada. (A Crítica de 10 março de 1961)

Toda esta característica performática do cantor exposta no jornal A Crítica nos faz analisar que a interpretação musical era bastante expressiva tanto na voz quanto nos gestos, muito utilizada nos filmes musicais.

A vinda desses cantores que se apresentavam nos cinemas e/ou faziam parte dos filmes musicais favoreceu que muitos jovens, que estavam se inserindo nas práticas musicais da cidade, fizessem o mesmo que Orlando Dias fez quando juntou a voz e a interpretação de cada cantor que estava em sucesso.

O cinema, então, passou a ser um local de aprendizado musical: era participando das sessões de cinema que o jovem aprendia a tocar no instrumento musical, as músicas de sucesso, como o violão, a guitarra e a bateria, e também aprendiam as performances dos cantores nacionais e internacionais.

Cabral (2011) nos indica que o cinema foi também uma forma de divulgação da música.

A música popular brasileira não se limitava ao disco, ao rádio, ao teatro e às apresentações públicas para chegar ao conhecimento do público. Desde 1929, embora timidamente, o cinema falado também passou a ser um veículo importante de divulgação musical. Mal surgiu a novidade nos Estados Unidos, alguns empresários brasileiros trataram de importar o novo equipamento de filmagem. (p. 41)

Os filmes americanos estavam no auge e neles sempre passavam as cenas dos cantores ou dos grupos, como por exemplo, os filmes que constantemente eram projetados com a participação de Elvis Presley, dentre eles: Love Me Tender, Loving You, Jalilhouse Rock (1957), King Creole, G.I. Blues, Blue Hawaii, Wild in The Country, Kid Galahad, Follow That Dream, Fun In Acapulco (1963) - O Seresteiro de Acapulco (BR), Viva Las Vegas (1964) - Amor a toda velocidade (BR), Roustabout. E The Beatles dentre eles A Hard Day's Night (1964), Help! (29 de julho de 1965), Magical Mystery Tour (1967), Let It Be (1970), além de gravarem a trilha sonora do desenho animado Yellow Submarine (1968).

A radialista Jerusa Santos (2012), em entrevista concedida, relata que nesse período havia muito filme musical em Manaus e relembra alguns filmes musicais como o Elvis, The Platters e a Orquestra Glenn Miller. 
É que naquela época tinha muito filme musical, do Elvis, eu não era muito de ir ao cinema, mas tinham os filmes musicais, os mexicanos, tinha tango, bolero, tinha filme americano também com muita música como The Platters, uma maravilha, eram quatro rapazes morenos e uma moça, era um conjunto que sempre estava em filme americano, tinha também a orquestra do Glenn Miller, fazia muito filme musical, dança, naquele tempo o Fox trotem, bolerão com a orquestra americana. Um dia desses passou o filme Música e Lágrima, eu fiquei esperando, era de madrugada.

Adorno (2002, p. 15) ressalta como era a reprodução exata do mundo nas telas do cinema: "A velha experiência do expectador cinematográfico, para quem a rua lá de fora parece a continuação do espetáculo que acabou de ver - pois este quer precisamente reproduzir de modo exato o mundo percebido continuamente - tornou-se o critério da produção".

Segundo Morin (1989, p. 47), a cidade de Hollywood, onde eram encenados os grandes filmes musicais, se transformou na cidade dos sonhos reais: "Evidentemente, Hollywood é o cenário maravilhoso onde a vida mítica é real e a vida real mítica. Estão lá os Champs Elysées: cidade lendária, mas que vive; um navio de sonhos, mas ancorado na vida real; um Shangri-lá californiano, onde corre o elixir da imortalidade”.

Em Manaus, essa vida real mítica se desdobrará no jovem querer ser o ídolo do cinema, querer representar tal e qual o cantor nos clubes da cidade, uma forma de viver um sonho hollywoodiano.

Logo, os jovens músicos que começavam a formar bandas ao formato americanizado de Beatles ou quem fazia dublagem para se apresentar nos clubes como laser e divertimento, tinham que assistir sessões e, mais sessões de cinema, para aprenderem os trejeitos dos cantores e aprenderem a tocar a música que estava sendo sucesso.

Menezes (2011) esclarece que, o objetivo para frequentar muitas sessões de cinema estava associado à reprodução das músicas de sucesso nas festas dos clubes da cidade.

Havia quem passasse sessões e mais sessões dentro do cinema, que começou a passar filmes de artistas que tocavam nos filmes, para aprender a tocar algumas canções, frequentar cinema em Manaus, também estava associado a oportunidade de ouvir novas canções e reproduzi-las para virar sucesso nas festas da cidade. (p. 48)

Como comenta Azancoth (Apud AGUIAR, 2000, p. 18): "uma tímida juventude transviada ensaiava tímidos passos de rock durante a exibição de 'O Balanço das Horas, no Cine Odeon”. Na década de 1960 era tarefa dos jovens nas apresentações nos clubes reproduzir o que se via no filme.

O cinema teve sua contribuição referente a visualização da performance do artista apresentado, um local apropriado para aqueles que tinham como objetivo o aprendizado musical, proporcionando novos circuitos musicais como as dublagens nos clubes da cidade.

\subsection{Dublagens e Festivais de dublagem}

As dublagens foram uma reprodução dos musicais do cinema: ir ao cinema era para melhorar as performances para se apresentar nos clubes ou nos programas de rádio na cidade de Manaus

Fazer dublagem era a forma de imitar os principais astros da época, seus ídolos, os que estavam no auge da música nacional e americana. Dublar em todos os sentidos: figurino, articulação, gestos, enfim, significava muito na época, era a representação personificada dos grandes cantores do rádio e do cinema. 
Benjamin (1969, p. 213) comenta que a "cada dia que passa, mais se impõe a necessidade de apoderar-se do objeto do modo mais próximo possível em sua imagem, porém ainda mais em sua cópia”. Ou seja, os jovens passaram a reproduzir outros cantores e se apoderaram de suas imagens e vozes.

A maior influência para a existência desta dublagem em Manaus foi o cinema que era muito presente. Os jovens que começavam a aprender as músicas iam várias vezes ao cinema; era uma possibilidade de aprender, principalmente porque ajudava a ver as performances dos cantores, os figurinos, as características, a forma de tocar e cantar, etc., pois nesse período iniciaram os grandes musicais de Hollywood, os musicais nacionais, e os conjuntos musicais e seus cantores estavam presentes nestes filmes, como comenta Azancoth (Apud Costa, 2000)

Foi através do cinema que comecei a perceber as primeiras mudanças no comportamento da juventude. O mundo estava mudando! E Manaus? Uma tímida juventude transviada ensaiava tímidos passos de rock durante a exibição de 'Ao Balanço das Horas', no Cine Odeon. (p. 120)

A tela do cinema, a voz que soa brilhantemente na rádio e no disco confundem com a realidade, a imitação justamente era a reprodução desse mundo das telas, do sonho americano.

Adorno (2002, p. 35) relata esse sonho americano reproduzido nas telas e sendo imitado nos espaços da cidade, em que: "toda voz de tenor soa exatamente como um disco de Caruso, e os rostos das garotas do Texas naturalmente se assemelham aos modelos segundo os quais seriam classificadas em Hollywood".

Este ambiente de formação musical através do cinema e de outros meios de comunicação e das performances pela dublagem motivou a formação de grupos e intérpretes em diferentes ambientes e espaços musicais na cidade: clubes, rádios e teatros. Assim como a realização de dois festivais de dublagem, 1965/1966, com os jovens da dublagem dos clubes sociais.

Com o aumento dos clubes pelo interesse pela dublagem, o comércio e as gravadoras aproveitaram para patrocinar um festival de dublagem. A dublagem nos clubes de Manaus motivou um cenário glamoroso de uma manifestação musical totalmente diferente do que aconteceu no cenário nacional: o Festival de Dublagem.

Ao apresentar no Festival de Dublagem os jovens queriam somente a fama. Imitar os gestos, gesticular com o corpo e com a boca, e o figurino igual ao cantor que a gravadora encomendava para dublar, significava ser artista, ter popularidade na cidade e, principalmente, alcançar o sucesso que tanto almejavam com a dublagem: querer ser o próprio artista que imitava.

Os Festivais de Dublagem foram praticamente um amadorismo ou uma releitura dos filmes que eram vistos em Manaus, e a maioria era de filmes musicais internacionais produzidos em Hollywood, como os filmes que tinham Elvis Presley ${ }^{3}$, que era um dos mais considerados nomes em filmes musicais.

A partir de 1967, os conjuntos musicais dessa juventude da década de 1960 não dublavam mais, mas executavam o instrumento musical, com uma formação mais técnica e também influenciada pela música dos Beatles e da Jovem Guarda, bem como com a compra de melhores equipamentos advindo da Zona Franca de Manaus.

Portanto, foi assim que alguns jovens da década de 1960 iniciaram suas trajetórias musicais e a música em Manaus se moldou aos recursos que esses jovens tinham para se legitimarem no circuito cultural da cidade. 


\section{Diálogos e Considerações finais}

O cinema esteve muito presente como atividade cultural na cidade de Manaus. Ele congregava os festejos de aniversários, servia de ponto de encontro entre jovens para se divertir. A cidade também entrou no clima dos filmes americanos e isso chamava a atenção dos jovens que iam a cinema aprender como o cantor se comportava em palco, seus jeitos e vestimentas, enfim, foi uma cartilha em formato de tela.

Muitos jovens que estavam aprendendo a tocar um instrumento viam sessões várias vezes para aprender os acordes da música ou mesmo para imitar os ídolos nos clubes e nas festas da cidade.

É importante frisar, que o cinema em Manaus, especificamente esta atividade que os jovens faziam em ir ao cinema e assistir várias sessões para aprender, criou-se uma rotina por eles e foi fundamental para desenvolver os gestos e vestimentas dos ídolos que posteriormente seriam imitados ou

Uma vida real mítica de representar o sonho de ser ídolo, assim como os artistas do cinema que se transformaram em estrelas ou deuses. Consequentemente as dublagens em Manaus foram o retrato das performances musicais do cinema, sem a imagem, os jovens não teriam referência para reproduzir, aprender e assim ganhar status de ser reconhecido como ídolo na cidade.

\section{Notas}

1 Este trabalho faz parte dos resultados da pesquisa da dissertação de mestrado intitulada As inter-relações socioculturais na vida musical de Manaus na década de 1960, a qual aborda sobre o rádio, o cinema e os jornais e suas mediações com o circuito musical em Manaus na década de 1960. A Dissertação foi apresentada em 2012 para o Programa de Pós-Graduação Sociedade e Cultura na Amazônia-PPGSCA, da Universidade Federal do Amazonas - UFAM/AM, orientada pela Profa. Dra. Rosemara Staub de Barros Zago.

2 Doutorado em andamento pelo Programa de Pós-Graduação Sociedade e Cultura na Amazônia-PPGSCA-UFAM, linha de pesquisa 1: processos simbólicos e manifestações socioculturais na Amazônia, orientadora Profa. Dra. Rosemara Staub de Barros Zago, ano de ingresso 2015.

3 Os seguintes filmes são considerados bons ou ótimos, tanto pelas coreografias, músicas e principalmente a participação de Elvis: Love Me Tender, Loving You, Jalilhouse Rock (1957), King Creole, G.I. Blues, Blue Hawaii, Wild in The Country, Kid Galahad, Follow That Dream.

\section{Referências}

A CRÍTICA, Grande estreia de Orlando Dias. Manaus, 10 mar. 1961.

ADORNO, Theodor W. Indústria Cultural e Sociedade. 7. ed. Seleção de textos Jorge Matos Brito de Almeida; traduzido por Julia Elisabeth Levy, [et al.]. São Paulo: Paz e Terra, 2002.

. O fetichismo na música e a regressão da audição. In Textos Escolhidos. São Paulo: Nova Cultural, 1996.

AGUIAR, José Vicente de Souza. Manaus: praça, café colégio e cinema nos anos 50 e 60. Manaus: Universidade do Amazonas, 2000.

BENJAMIN, Walter. A obra de arte na época da sua reprodutibilidade técnica. In LIMA, Luis Costa. Teoria da Cultura de Massas. Rio de janeiro: Saga, 1969.

BLOOM, Harold. A Angústia da Influência: uma teoria da Poesia. Tradução de Arthur Nestrovski. Rio de Janeiro: Imago, 1991. 
CABRAL, Sérgio. MPB na era do Rádio. São Paulo: Lazuli Editora, 2011.

FUBINI, Enrico. Estética da Música. Tradução Sandra Escobar. Lisboa: Biblioteca Nacional de Portugal, Edições 70, 2003.

MENEZES, Mauro Augusto Dourado. Eu canto pra falar do Amazonas: uma visão das narrativas musicais em Manaus. Dissertação de mestrado do Curso de Pós-Graduação Sociedade e Cultura na Amazônia da Universidade Federal do Amazonas: Manaus, 2011.

MORIN, Edgar. Cultura de massas no século XX: o espírito do tempo II NECROSE. Com a colaboração de Irene Nahoum, tradução de Agenor Soares santos. Rio de Janeiro: Forense-Universitária, 1977.

AFONSO, Lucyanne de Melo. Entrevista de Maria Jerusalém dos Santos em 06 de novembro de 2012. Manaus. Gravação em gravador portátil. Residência da entrevistada, Cidade Nova.

SANTOS, Milton. A Natureza do espaço: técnica e tempo, razão e emoção. 3. ed. São Paulo: Hucitec, 1999.

. Por uma outra globalização: do pensamento único à consciência universal. 6. ed. Rio de Janeiro: Record, 2001.

SANTOS, Izequias Estevam dos. Manual de métodos e técnicas de pesquisa científica. 7. ed. Ver., atual. E ampl. Niterói, RJ: Impetus, 2010.

SEREN, Lucas. Gosto, música e juventude. São Paulo: Annablume, 2011.

TINHORÃO, José Ramos. Música Popular: um tema em debate. 3. ed. rev. e amp. São Paulo: Ed. 74, 1997.

Lucyanne de Melo Afonso - Professora do Curso de Música da Universidade Federal do Amazonas. Doutorado em andamento em Sociedade e Cultura na Amazônia (UFAM). Mestre em Sociedade e Cultura na Amazônia (PPPGSCA - UFAM/2012), especialista em Musicoterapia pelo Conservatório Brasileiro de Música/RJ (2003) e graduada em Licenciatura Plena em Educação Artística - Música pela UFAM (2001). Atua nas áreas de educação musical, musicoterapia, música popular e sociedade e cultura/música na Amazônia. 